\title{
AN INFLATION-BASED MAINTENANCE SCHEDULING MODEL
}

\author{
S.A.Oke ${ }^{1}$ and O.E. Charles-Owaba ${ }^{2}$ \\ ${ }^{1}$ Department of Mechanical Engineering \\ University of Lagos, Nigeria \\ ${ }^{2}$ Department of Industrial and Production Engineering \\ University of Ibadan, Nigeria \\ sa_oke@yahoo.com
}

\begin{abstract}
This paper attempts to extend an original Gantt-charting model for optimal maintenance scheduling of multiple facilities in multiple periods credited to CharlesOwaba. In particular, an inflationary factor is incorporated into the period-dependent cost function element of the model. Some computational experimentation on the new model is tested. This work is perhaps the first to advance the extension of the Optimal Gantt Charting (OGC) model in terms of inflation. The work presents a wealth of research opportunities and has at least the modest potential to evaluate maintenance scheduling theory into the ranks of major theories of maintenance.
\end{abstract}

\section{OPSOMMING}

Die artikel poog om inflasie te akkommodeer binne die raamwerk van ' $n$ Ganttkaartmodel vir die bepaling van optimum skedulering van instandhouding vir meervoudige fasiliteite met die verloop van tyd. Inflasie vorm dus deel van die koste-element van die model. Die model is ook op 'n beperkte wyse gevalideer met behulp van ' $\mathrm{n}$ rekenaarstudie. Die verkreë resultate toon dat addisionele navorsing gedoen kan word om sodoende die metode te vestig in die voorste rang van instandhoudingsbeplanning 


\section{INTRODUCTION}

Over the past several years, the maintenance scheduling literature has experienced an impressive number of criticisms and established research methods and philosophy $[23,31,46,70,75]$. Although these topics have been discussed in print for some years, the frequency and magnitude of recent criticisms seem unprecedented. Dissatisfaction has been framed in terms of a variety of different issues. This includes the descriptive rather than action-taking orientation of findings, the emphasis on theory at the expense of practicality of findings, complexity of solutions at the expense of limited applications, dearth of statistical techniques in analytical frameworks, etc.

The breadth and intensity of the criticism seem to be signaling the beginnings of an important re-evaluation of some of the foundation values in the field. Some researchers have concluded that there is a crisis of usefulness of some research findings in the maintenance field generally. The question of traditional research philosophy that treats preventive maintenance scheduling in terms of a number of policies, which are often impractical in nature, has advanced to the point that some of the greatest minds of our time have questioned the appropriateness of the various approaches adopted [27,39,40,47,54,73]. The author presents criticism of the field, but rather focusses on how to solve one of these key problems which is considered as fundamental to the development of the maintenance scheduling field.

This thesis is an invitation to engage in an exercise of simultaneous scheduling of both maintenance and operational activities involving a large number of machines and a limited number of service men based on the physical attributes of both subsystems. The intention is to consciously examine and debate the frameworks, assumptions, applicability, limitations, and optimality conditions of the maintenance scheduling problem.

The model considered is an extended work of Charles-Owaba [12]. The optimal Gantt Charting (OGC) model is extended to incorporate inflationary factors due to price changes in operational cost components.

This is a worthwhile contribution to knowledge. Solving the maintenance scheduling problem with the use of a transportation model goes beyond mere recognition of an NP-simple solution procedure. One implication is that the challenge of simultaneous scheduling of maintenance and operational activities is more complicated than the traditional scheduling of operational activities in discrete manufacturing systems. Determination of limiting conditions, optimality of schedules and other aspects of modeling are complicating aspects of combining maintenance and operations scheduling.

A second implication of the research is that a better relationship between the operations and the maintenance groups is enhanced since optimality of schedules is considered, and intricate problems in each group resolved [2, 8, 11, 13]. Conflict will be resolved to a great extent through this activity. A third implication is that efforts to improve the understanding of maintenance and operations scheduling might 
benefit from addressing factors militating against a full appreciation of the problem. Clearly, more research is suggested to properly portray the characteristics of such optimal scheduling of operations and maintenance activities, and to test and expand our impressions. At the current rate of technological exposition, research into scheduling of both maintenance and operations under technological classifications are ripe for study. Several other lines of research are also suggested from our analysis crying for empirical research.

\section{LITERATURE REVIEW}

The literature on maintenance scheduling is wide-ranging, covering areas in electrical, civil, highway and industrial engineering [21, 22, 26, 28, 29]. The motivation for this work lies in the further call for research investigations on resource-constrained scheduling of maintenance and operations by Oke [51]. The author identified the need to develop variants of optimal solutions for existing scheduling problems in both manufacturing and service industries based on the original work by Charles-Owaba [12]. The current work explores the possibility of extending the existing framework by incorporating the inflation factor that has been neglected till date in the original model.

The approach used in reviewing the English language literature that covers the wide range of the topic discussed in this paper is to examine maintenance scheduling and economics literature $[1,3,14,15,19]$. For the economics literature, particular focus is given to a myriad of studies on inflation and engineering economics [43, 44, 53, $63,69,72]$. Thus, in this work, a careful outline of studies relating to this subject is presented.

The maintenance scheduling literature has been broadly classified as both quantitative and qualitative $[16,17,51]$. The scope of work on the maintenance scheduling literature includes approaches, optimality studies, algorithms, techniques, constraints and limitations. Approaches in Maintenance Scheduling research include, but are not limited to, multistage, system, probabilistic [48], fuzzy modeling $[19,25]$ and CPM with a bill of materials. Several effective and sufficient techniques have been suggested as alternatives to traditional optimization-based techniques where the problem size is large and exact optimal solution is not available. The modern techniques include simulated annealing [59], genetic algorithms [7, 10, 20, 65, 71], heuristics [62], memetics [9], and hybrids.

Various optimization studies have also been conducted, including by Billinton and Pan [6], Charles-Owaba [12], Christiaanse [16], El-Sharkh [25], Yamayee et al. [74], and Zurn and Quintana [76,77]. Models have been developed for different situations: proportional intensities, full history, warranted products, finite source, uncertainty, deregulated systems and planning. The constraints under which models operate include: sparse data, risk, and network. Several tools have also been applied. However, simulation appears to be the most significant. Examples are in the studies due to Anily [4,5], Egan [24], and Contaxis et al. [18]. 
In all, the closest studies to the current one are largely due to Charles-Owaba [12] and Oke [51]. Unfortunately, none of these studies seem to have investigated the incorporation of the inflation factor into the existing structure. Perhaps the studies are justified due to the level of knowledge development in the area when the works were published. For example, Charles-Owaba [12] probably focused on defending the position that it is feasible to schedule maintenance and operations simultaneously even though the problem had not been visited in the literature.

In the case of Oke [51], the work is exclusively a literature review, which did not expatiate on how to incorporate the inflation factor into the existing model. No mathematical assistance was given in this regard. Therefore, the current work is justified in closing this important gap by providing a rich source of information for those interested in the economics of maintenance scheduling. The other body of knowledge reviewed here relates to the engineering economics literature. This body of knowledge only presents ideas and a usefulness of incorporating inflation factors into the existing framework of modeling engineering problems. However, no mention was made about maintenance scheduling in particular. The support for this statement could be found in Park [52] and Sepulveda et al. [60].

In the general inflation literature, a number of investigations that may benefit maintenance scheduling researchers have been made [30, 32-38, 41, 42, 45, 74]. For example, a relationship could be established between maintenance and productivity while inflation stands as a linkage [53]. Another case may be an understanding of the assessment of maintenance scheduling based on inflation forecasting and its relationship to scheduling facilities for maintenance [61, 64, 66-68]. A further study [63] that relates human capital and inflation could be extended to the maintenance scheduling system where the personnel that drives the system could be mathematically related in equations concerning inflation and maintenance scheduling. Other studies are useful to support the literature reviewed in this work $[69,72]$. In all, the literature search gives the information to conclude that in the maintenance scheduling literature, engineering economics literature or the inflation literature, no study exists that has documented optimal scheduling of resourceconstrained maintenance and operations with inflation [48-50, 55-58,61]. This is therefore justification for the current study.

\section{MODEL FRAMEWORK}

The specific problem is defined in general terms as follows:

"Given a set of $M$ machines for preventive maintenance and operations in $T$ contiguous periods, limited periodic maintenance capacity $\left(A_{j}\right)$, duration $\left(B_{j}\right)$ per maintenance visit, arrival periods $\left(k_{i}\right)$ and number of visits per machine $\left(N_{i}\right)$ select the periods for alternating preventive maintenance and operations such that the total preventive maintenance cost is a minimum".

A theoretical framework for the model is built on the assumptions that a cycle of activities occurs in maintenance - operation order, the total number of maintenanceoperation periods ( $\mathrm{T}$ ) are fixed and contiguous, and an arriving machine has its 
maintenance activities commenced only when resources are available. The criterion is the minimisation of preventive maintenance cost subject to the constraint that maintenance capacity is limited (see figure 1).

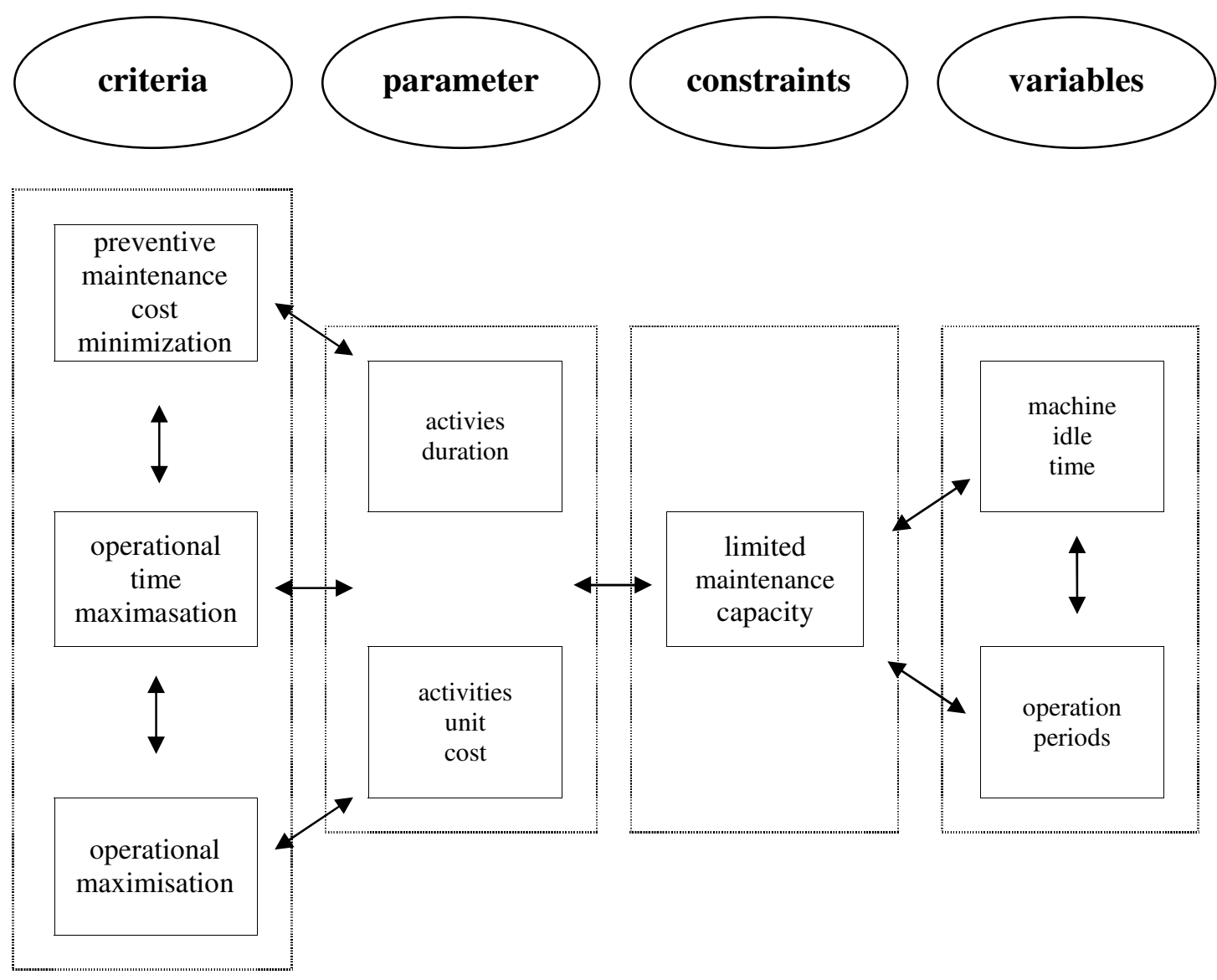

\section{Figure 1: Structural Model of Charles-Owaba's OGC model}

The mathematical definition of the model that defines the Gantt-charting problem is as follows:

$$
\text { Minimize } \mathrm{C}\left(\mathrm{T}, \mathrm{M}, \mathrm{Y}_{\mathrm{ij}}\right)=\sum_{\mathrm{i}=1}^{\mathrm{M}} \sum_{\mathrm{j}=1}^{\mathrm{T}} \mathrm{C}_{\mathrm{ij}} \mathrm{Y}_{\mathrm{ij}}(1+\alpha)^{\mathrm{j}}
$$

Subject to:

$$
\sum_{\mathrm{i}=1}^{\mathrm{M}} \mathrm{Y}_{\mathrm{ij}} \leq \mathrm{A}_{\mathrm{j}} \quad \text { (maintenance capacity constraint) }
$$

and

$$
\sum_{j=1}^{T} Y_{i j}=\sum_{r=1}^{N i} B_{i}^{r} \quad \text { (maintenance period constraint) }
$$


Given that,

$$
C_{i j}=\left\{\begin{array}{l}
a_{i}+d_{i}\left(j-k_{1}\right), \text { if }(j-k) \geq 0 \\
\infty, \text { otherwise (infeasible alternative) }
\end{array}\right.
$$

where, $a_{i}$ and $d_{i}$ are cost parameters, $j=$ period, $k_{i}=$ arrival period, and $\alpha=$ inflation factor.

The following notations are also true as defined by Charles-Owaba [12]:

(i) $\quad \mathrm{C}_{\mathrm{ij}}$ represents the unit cost of maintenance of machine $\mathrm{i}$ during period $\mathrm{j}$

(ii) $\mathrm{Y}_{\mathrm{ij}}$ is defined as the Gantt charting variable that is expressed in a binary form with values 1 and 0 . These variables take on the value 1 the condition that machine $i$ was actually maintained in period $j$ and it takes on a value of zero if the situation is otherwise

(iii) $\mathrm{m}$ denotes the total number of machines in the maintenance system

(iv) T represents the total number of periods in the planning horizon

(v) $A_{j}$ is the maintenance capacity at period $j$

(vi) $\mathrm{B}_{\mathrm{i}}^{\mathrm{r}}$ is the number of periods needed to maintain machine $\mathrm{i}$ at the $\mathrm{r}^{\text {th }}$ visit

(vii) $\mathrm{N}_{\mathrm{i}}$ is the total number of visits machine $\mathrm{i}$ can make for maintenance within the time horizon

(viii) $\alpha$ is the period dependent inflation factor which may be approximated by the current bank interest rate which can be short term, medium term, or long term according to the situation.

Now, knowing that maintenance capacity is highly dependent on the arrival and departure rates of the facilities serviced, it is necessary to model the arrival and service rates according to a particular pattern. Most practical situations relate the patterns to the Poisson distribution. Thus, for the purpose of practicability of the model, the arrival and service rates are assumed to be Poisson, and hence models an equivalence of maintenance capacity parameter as such. Therefore let

$$
A_{j}=\frac{M^{j} e^{-M}}{j !}
$$

Equation(2) then becomes,

$$
\sum_{i=I}^{M} Y_{i j} \leq \frac{M^{j} e^{-M}}{j !}
$$


Considering a situation whereby the " $\leq$ " is converted to "=", then

$$
\sum_{i=I}^{M} Y_{i j}=\frac{M^{j} e^{-M}}{j !}
$$

From equation (1) it follows that

$$
\mathrm{C}\left(\mathrm{T}, \mathrm{M}, \mathrm{Y}_{\mathrm{ij}}\right)=\sum_{\mathrm{i}=\mathrm{I}}^{\mathrm{M}} \sum_{\mathrm{j}=\mathrm{I}}^{\mathrm{T}} \mathrm{C}_{\mathrm{ij}} \mathrm{Y}_{\mathrm{ij}}(\mathrm{I}+\alpha)^{j}
$$

But $\quad \sum_{i=I}^{M} \sum_{j=I}^{T} C_{i j} Y_{i j}(I+\alpha)^{j}=\left(\sum_{j=I}^{M} C_{i j} Y_{i}\right)\left(\sum_{j=I}^{T} C_{i j} Y_{i j}(I+\alpha)^{j}\right)$

Also,

$$
\begin{aligned}
& \sum_{j=I}^{M} C_{i j} Y_{i j}=\sum_{j=I}^{M} C_{i j} \sum_{j=I}^{M} Y_{i j}-\left[\sum_{j=I}^{M} C_{i j} Y_{(i j)}+\sum_{j=I}^{M} C_{i j} Y_{(i j)}+\ldots+\sum_{j=I}^{M} C_{i j} Y_{(i-M) j}\right] \\
& -\left[\sum_{j=I}^{M} C_{(i-I) j} Y_{i j}+\sum_{j=I}^{M} C_{(i-2)} Y_{i j}+\ldots+\sum_{j=I}^{M} C_{(i-M) j} Y_{i j}\right]
\end{aligned}
$$

Similarly,

$$
\begin{aligned}
& \sum_{j=I}^{T} C_{i j} Y_{i j}(1+\alpha)^{j}=\sum_{j=I}^{T} C_{i j} \sum_{j=I}^{T} Y_{i j} \sum_{j=I}^{T}(1+\alpha)^{j} \\
& -\left[\sum_{j=I}^{T} C_{i j} Y_{i(j-1)}+\sum_{j=I}^{T} C_{i j} Y_{i(j-2)}+\ldots \mp \sum_{j=I}^{T} C_{i j} Y_{i(j-T)}\right] \\
& -\left[\sum_{j=I}^{T} C_{i(j-1)} Y_{i j}+\sum_{j=I}^{T} C_{i(j-2)} Y_{i j}+\ldots+\sum_{j=I}^{T} C_{i(j-T)} Y_{i j}\right] \\
& -\left[\sum_{\mathrm{j}=\mathrm{I}}^{\mathrm{T}}(1+\alpha)^{\mathrm{j}-1}+\sum_{\mathrm{j}=\mathrm{I}}^{\mathrm{T}}(1+\alpha)^{\mathrm{j}-2}+\ldots+\sum_{\mathrm{j}=\mathrm{I}}^{\mathrm{T}}(1+\alpha)^{\mathrm{j}-\mathrm{T}}+\right]
\end{aligned}
$$

But,

$$
\begin{aligned}
& \sum_{i=I}^{M} Y_{i j}=A_{j}=\frac{M^{j} e^{-M}}{j !} \\
& \sum_{j=I}^{T} Y_{i j}=\sum_{r=I}^{N_{i}} B_{i}^{r}
\end{aligned}
$$

Thus, from equation (7) 
http://sajie.journals.ac.za

$$
\mathrm{C}\left(\mathrm{T}, \mathrm{M}, \mathrm{Y}_{\mathrm{ij}}\right)=\left(\sum_{\mathrm{i}=\mathrm{I}}^{\mathrm{M}} \mathrm{C}_{\mathrm{ij}} \mathrm{Y}_{\mathrm{ij}}\right)\left(\sum_{\mathrm{j}=\mathrm{I}}^{\mathrm{T}} \mathrm{C}_{\mathrm{ij}} \mathrm{Y}_{\mathrm{ij}}(\mathrm{I}+\alpha)^{j}\right)
$$

Substituting the expression of $\sum_{\mathrm{i}=\mathrm{I}}^{\mathrm{M}} \mathrm{C}_{\mathrm{ij}} \mathrm{Y}_{\mathrm{ij}}$ and $\sum_{\mathrm{j}=\mathrm{I}}^{\mathrm{T}} \mathrm{C}_{\mathrm{i} j} \mathrm{Y}_{\mathrm{ij}}(\mathrm{I}+\alpha)^{j}$ into equation (7) gives

$$
\begin{aligned}
& C\left(T, M, Y_{i j}\right)=\left[=\sum_{i=I}^{M} C_{i j} \sum_{j=I}^{M} Y_{i j}-\right]\left[\sum_{i=I}^{M} C_{i j} Y_{(i-1) j}+\sum_{j=I}^{M} C_{i j} Y_{(1-2) j}+\ldots+\sum_{j=I}^{M} C_{i j} Y_{(1-m) j}\right]- \\
& \sum_{i=I}^{M} C_{(i-1) j} Y_{i j}+\sum_{j=I}^{M} C_{(i-2) j} Y_{i j}+\ldots+\sum_{j=I}^{M} C_{(i-m) j} Y_{i j} \\
& \left(\sum_{i=1}^{T} C_{i j} \sum_{j=1}^{T} Y_{i j} \sum_{j-1}^{T}(1+\alpha)^{j}-\left[\sum_{i=I}^{T} C_{i j} Y_{i(i-1) j}+\sum_{j=I}^{T} C_{i j} Y_{i(1-2) j}+\ldots+\sum_{j=I}^{T} C_{i j} Y_{i(1-T) j}\right]-\right. \\
& {\left[\sum_{i=I}^{T} C_{i(j-1)} Y_{i j}+\sum_{j=I}^{T} C_{i(j-2)} Y_{i j}+\ldots+\sum_{j=I}^{T} C_{i(j-T)} Y_{i j}\right]-} \\
& \left.\left[\sum_{i=I}^{T} C_{(i-\alpha)}-1+\sum_{j=I}^{T} C_{(i-\alpha)}\right)^{j-2}+\ldots+\sum_{j=I}^{T} C_{(i-\alpha)}\right]
\end{aligned}
$$

Putting $\sum_{\mathrm{i}=1}^{\mathrm{M}} \mathrm{Y}_{\mathrm{ij}}=\frac{\mathrm{M}^{\mathrm{j}} \mathrm{e}^{-\mathrm{M}}}{\mathrm{j} !}$ and $\sum_{\mathrm{j}=\mathrm{I}}^{\mathrm{T}} \mathrm{Y}_{\mathrm{ij}}=\sum_{\mathrm{r}=1}^{\mathrm{N}_{i}} \mathrm{~B}_{\mathrm{i}}^{\mathrm{r}}$ gives

$$
\begin{aligned}
& C\left(T, M, Y_{i j}\right)=\left(\sum_{i=I}^{M} C_{i j}\right)\left(\frac{M^{j} e^{-m}}{j !}\right)-\left[\sum_{i=I}^{M} C_{i j} Y_{(i-1) j}+\sum_{j=I}^{M} C_{i j} Y_{(1-2) j}+\ldots+\sum_{j=I}^{M} C_{i j} Y_{(1-m) j}\right]- \\
& {\left[\sum_{i=I}^{M} C_{(i-1) j} Y_{i j}+\sum_{j=I}^{M} C_{(i-2) j} Y_{i j}+\ldots+\sum_{j=I}^{M} C_{(i-m) j} Y_{i j}\right]} \\
& \left(\sum_{j=I}^{T} C_{i j} \sum_{r=1}^{N_{i}} B_{i}^{r}(1+\alpha)^{j}-\left[\sum_{i=I}^{T} C_{i j} Y_{i(i-1)}+\sum_{j=I}^{T} C_{i j} Y_{i(1-2) j}+\ldots+\sum_{j=I}^{T} C_{i j} Y_{i(1-T)}\right]-\right. \\
& {\left[\sum_{i=I}^{T} C_{i(i-1)} Y_{i j}+\sum_{j=I}^{T} C_{i(i-2) j} Y_{i j}+\ldots+\sum_{j=I}^{T} C_{(i-T) j} Y_{i j}\right]-} \\
& \left.\left[\sum_{i=I}^{T} C_{(i-\alpha)^{j}-1}+\sum_{j=I}^{T} C_{(i-\alpha)^{j-2}}+\ldots+\sum_{j=I}^{T} C_{(i-\alpha){ }^{j-T}}\right]\right)
\end{aligned}
$$

130 
For other expressions for $\mathrm{C}\left(\mathrm{M}, \mathrm{T}, \mathrm{Y}_{\mathrm{ij}}\right)$

Similarly,

$$
\begin{aligned}
& C\left(M, T, Y_{i j}\right)=\sum_{i=1}^{M} \sum_{j=1}^{T} C_{i j} Y_{i j} e^{(1+\alpha) j} \text { can be generally written as: } \\
& C\left(T, M, Y_{i j}\right)=\left(\sum_{i=1}^{M} C_{i j}\right)\left(\frac{M^{j} e^{-m}}{j !}\right)-\left[\sum_{i=1}^{M} C_{i j} Y_{(i-1) j}+\ldots+\sum_{j=1}^{M} C_{i j} Y_{(1-m) j}\right]- \\
& {\left[\sum_{j=I}^{M} C_{(i-2) j} Y_{i j}+\ldots+\sum_{j=I}^{M} C_{(i-m) j} Y_{i j}\right]} \\
& \left(\sum_{j=I}^{T} C_{i j} \sum_{r=1}^{N_{i}} B_{i}^{r} \sum_{j-1}^{T}(1+\alpha)^{j}-\right. \\
& {\left[\sum_{j=I}^{T} C_{i j} Y_{i(j-1)}+\ldots+\sum_{j=I}^{T} C_{i j} Y_{i(j-T)}\right]-\left[\sum_{j=I}^{T} C_{i(i-1) j} Y_{i j}+\ldots+\sum_{j=I}^{T} C_{(i-T) j} Y_{i j}\right]-} \\
& \left.\left[\sum_{j=I}^{T} e^{(i-\alpha)^{j-2}}+\ldots+\sum_{j=I}^{T} e^{(i-\alpha)^{j-T}}\right]\right)
\end{aligned}
$$

It should be noted that similar analyses could be done for equations whose objective functions are different from the one treated above. The objective function in the definition above may be written in different forms according to the nature of inflation that exists in the environment being studied. Common experience reveals that equation (1) holds for economies that have a stabile inflationary rate like United Kingdom. However, for other environments such as the developing countries as Africa, Asia and the Caribbeans, the following variants of equation (1) may hold:

$$
\begin{aligned}
& \mathrm{C}\left(\mathrm{T}, \mathrm{M}, \mathrm{Y}_{\mathrm{ij}}\right)=\sum_{\mathrm{i}=1}^{\mathrm{M}} \sum_{\mathrm{j}=1}^{\mathrm{T}} \mathrm{C}_{\mathrm{ij}} \mathrm{Y}_{\mathrm{ij}} \mathrm{e}^{(1+\alpha)^{\mathrm{j}}} \\
& \mathrm{C}\left(\mathrm{T}, \mathrm{M}, \mathrm{Y}_{\mathrm{ij}}\right)=\sum_{\mathrm{i}=1}^{\mathrm{M}} \sum_{\mathrm{j}=1}^{\mathrm{T}} \mathrm{C}_{\mathrm{ij}} \mathrm{Y}_{\mathrm{ij}} \operatorname{Sin}^{2}(1+\alpha)^{\mathrm{j}} \\
& \mathrm{C}\left(\mathrm{T}, \mathrm{M}, \mathrm{Y}_{\mathrm{ij}}\right)=\sum_{\mathrm{i}=1}^{\mathrm{M}} \sum_{\mathrm{j}=1}^{\mathrm{T}} \mathrm{C}_{\mathrm{ij}} \mathrm{Y}_{\mathrm{ij}}\left(\mathrm{a}^{2}+\alpha^{\mathrm{j}} \mathrm{b}\right) \\
& \mathrm{C}\left(\mathrm{T}, \mathrm{M}, \mathrm{Y}_{\mathrm{ij}}\right)=\sum_{\mathrm{i}=1}^{\mathrm{M}} \sum_{\mathrm{j}=1}^{\mathrm{T}} \mathrm{C}_{\mathrm{ij}} \mathrm{Y}_{\mathrm{ij}} \mathrm{e}^{\mathrm{asin}(1+\alpha)}{ }^{\mathrm{j}}
\end{aligned}
$$

where $\mathrm{e}=2.718$, $\mathrm{a}$ and $\mathrm{b}$ are constants. 


\section{DATA ANALYSIS AND DISCUSSION OF RESULTS}

Having developed a model that is inflation-based, the need to test it with data becomes important. An effort was made to generate data through scientific simulation such that an adequate representation of the real behaviour of the system is mimicked. The use of manual simulation method may be tedious and uneconomical. Therefore, a computer programme was developed and run in Q-basic to generate the required data for testing the model. The programme and the results are shown in the appendix. Based on this, a selection of graphical representations of the results are displayed in figures 1 to 4 (see appendix).

An inquisitive reader may ask: what are we going to learn from the data generated and plotted as graphs? A first implication of the data analysis is that in practice, practitioners should take the maximum advantage of utilizing the computer tools in analyzing large volumes of data since repetition in manual data treatment may introduce errors into the results. Consequently, wrong decisions could be made due to the data errors. Another implication is that it is totally complex and nearly impossible to manage data for a large number of facilities to be maintained without the use of a computer. From the results generated of the total preventive maintenance cost, it is possible to predict future maintenance expenditure due to the scheduling of facilities and operations.

\section{CONCLUSIONS AND FUTURE DIRECTIONS}

Research on maintenance scheduling has steadily increased over the past several decades. In today's very competitive operations, production and marketing, greater demands are placed on companies to improve their products and processes in terms of both performance and cost. This involves considerable investment to optimize existing systems and innovative new concepts. Maintenance scheduling research has evolved as a successful effort in achieving this objective. While a number of innovative and up-to-date approaches exist in the literature, some gaps are created necessitating the development of robust, practical and theoretically based frameworks for complex systems. The case of multiple facilities maintainable in multiple periods is of paramount importance and has been addressed in this work.

There is currently a great need for an article that presents an economic-based viewpoint of the maintenance scheduling models. One of these models deals with the simultaneous scheduling of maintenance and operations in a resource-constrained environment. The results of the study are captured in an integrated and concise manner that reveals the critical variables of the economics of maintenance scheduling. Given the fact that the readers of this article may contend with a number of questions, three of these questions are addressed to justify the current work: (i) what are we going to learn from the article that we do not know now? (ii) why is it worth knowing? (iii) how will we know that all conclusions are valid?

In particular, the problem addressed in this work is the incorporation of the inflation factor in the model that exists on optimal maintenance scheduling. The article shows that the inflation factor has a significant influence on the key results obtained from 
modeling. Depending on the situation, the period dependent inflation factor may be approximated by the current bank interest rate. The interest rate may be of short, middle or long-term. It may also depend on the environment, which may be stable or unstable. We assumed a Poisson distribution for the arrival and departure rates, since it is the most frequently experienced distribution pattern in maintenance practice. With this assumption we were able to link the maintenance capacity function with the overall model, thus presenting a holistic perspective of maintenance modeling.

From the literature review, modeling and analysis carried out in this work, a number of important issues emerge. Consider the case of deflation instead of inflation, how will this affect the model? Assuming that technological changes of the equipment play a role in maintenance scheduling, how will this affect the modeling and the results obtained from it? Another point of interest is the 'based period issue'. Assuming that the productivity and the effectiveness of the maintenance scheduling activities are to be assessed, how to create a computation table that would take care of the base and current periods of measurement. In the same way that some other work has integrated productivity in maintenance scheduling modeling, future work could attempt to integrate the inventory concept into the existing structure of the maintenance scheduling model presented here.

Variants of inventory related work may include: (i) maintenance scheduling with a gradually replenished economic order quantity of inventory materials for use, (ii) maintenance scheduling with an inventory economic order quantity permitting stock out. The third variant may be a maintenance scheduling-inventory model integration with discount allowed. Future studies could also investigate the sensitivity of the model to determine the degree of responsiveness of changes in model parameters to output values.

Now, addressing the second question, why is it worth knowing? There are a number of supporting issues to justify the need for the current study. The first issue viewing maintenance scheduling from the point of incorporating inflation gives a holistic perspective of the model. Secondly, precision in model computation is introduced. For large complex systems, the changes introduced due to the inflation factor may be significant enough to give pointers for incorrect decision making on maintenance inventory materials. Viewing maintenance scheduling from the economics perspective invites scholars from other disciplines to engage in bi-disciplinary research activities that would enrich scholarship with more practically focused research than is presently obtained.

On the issue of validity of the model, tests employing empirical data prove the authenticity of the claim. Thus the analysis carried out in the relevant sections of this paper enriches this argument of model validity. However it has not been extensively tested since very limited data is used in view of time and other resource constraints. This work is perhaps the initial advance in extending the OCG model to include inflation. The work presents a wealth of research opportunities and has at least the modest potential to evaluate the maintenance scheduling theory into the ranks of major theories of maintenance. Future research is expected to introduce soft computing tools into this framework to expand its scope of applicability. For 
example, neurofuzzy, genetic algorithm, and artificial neural networks may be used for extending the existing framework in this study. The attempt made here hopefully stimulates research and the rethinking of optimal maintenance scheduling in a decade of increasing system complexity.

\section{REFERENCES}

[1] Aiken, M., 1999. "Using a neural network to forecast inflation", Industrial Management and Data Systems, Vol. 99, No. 7, pp. 296 - 301.

[2] Alfares, H.K., 1999. "Aircraft maintenance workforce scheduling: A case study", Journal of Quality in Maintenance Engineering, vol. 5, No. 2, pp. 7888.

[3] Al-Khazali, O., 1999. "Nominal interest rates and inflation in the PacificBasin Countries", Management Decision, Vol. 37. No. 2.

[4] Anily, S., Glass, C.A., Hassin, R., 1998. "The scheduling of maintenance service", Discrete Applied Mathematics, Vol. 82, pp. 27-42.

[5] Anily, S., Glass, C.A., Hassin, R., 1999. "Scheduling of maintenance services to three machines", Annals of Operations Research, Vol. 86, pp. 375-391.

[6] Billinton, R. and Pan, J., 1998. "Optimal maintenance scheduling in a two identical component parallel redundant systems", Journal of Reliability Engineering and System Safety, Vol. 59 No. 3, pp. 309-316.

[7] Burke, E.K., Clark, J.A., Smith, A.J., "Four methods for maintenance scheduling", In Proceedings of the International Conference on Artificial Neural Networks and Genetic Algorithms, pp. 264-269, Springer.

[8] Burke, E.K. and Smith, A.J., 1999. "A multi-stage approach for the thermal generator maintenance scheduling problem", Proceedings of the Congress on Evolutionary Computation (CE'99), Washington DC, USA (IEEE Press), Vol. 2, pp. 1085-1092.

[9] Burke, E.K. and Smith, A.J., 1999. "A memetic algorithm to schedule grid maintenance", Proceedings of the International Conference on Computational Intelligence for Modelling Control and Automation: Evolutionary Computation and Fuzzy Logic for Intelligent Control, Knowledge Acquisition and Information Retrieval, Vienna, IOS Press, pp. 122-127.

[10] Cavory, G., Dupas, R., Goncalves, G., 2001. "A genetic approach to the scheduling of preventive maintenance tasks on a single product manufacturing production line", International journal of Production Economies, Vol. 74, Issue 1-3, pp. 135-146.

[11] Charest, M., Ferland, J.A., 1993. "Preventative maintenance scheduling of power generation units", Annals of Operational Research, Vol. 41, pp. 185206.

[12] Charles-Owaba, O.E., 2002. "Gantt charting multiple machines' preventive maintenance activities", NJERD, Vol. 1, No. 1, pp. 60-67.

[13] Chattopadhyay, D., Bhattacharya, K., Pariksh, J., 1995. "A system approach to least-cost maintenance scheduling for an interconnected power system", IEEE Transactions on Power Systems, Vol. 10, No. 4, pp. 2000-2007.

[14] Chen, L.N., Toyoda, J., 1990. "Maintenance scheduling based on two level hierarchical structure to equalize incremental risk", IEEE Transactions on Power Systems, Vol. 5, No. 4, pp. 1510-1516. 
[15] Cheung, K., Hui, C., Sakamoto, H., Hirata, K., O'Young, L., 2004. “An evolutionary programming-based solution methodology for power generation and transmission maintenance scheduling", electric power systems research", Vol. 65, Issue 1, April, 2003, pp. 35-40.

[16] Christiaanse, W.R., 1973. "A program for calculating optimal maintenance schedules recognising constraints", 1973 PICA Conference Proceedings, pp. 230-239.

[17] Christiannse, W.R., Palmer, A.H., 1991. "A technique for automatic scheduling of the maintenance of generating facilities", IEEE Transactions on Power Apparatus and Systems, PAS-91, No. 1, pp. 319-327.

[18] Contaxis, G.C., Kavatza, S.D. Vournas, C.D., 1989. "An interactive package for risk evaluation and maintenance scheduling", IEEE Transactions on Power Systems, Vol. 4 No. 2, pp. 389, 395.

[19] Coudert, T., Grabot, B., Archimede, B., 2000. "Integration of maintenance constraints in scheduling: fuzzy modelling and multi-agent approach", $4^{\text {th }}$ IEEE/IFIP International Conference on Information Technology for Balanced Automation Systems in Production and Transportation (BASYS 2000), Berlin, Allemagne, 27-29, in Advances in Networked Entreprises, L.M. CamarinhaMatos, H. Afsarmanesh, H.H. Erbe Eds, Kluwer, 2000, pp. 297-304.

[20] Dahal, K. P., McDonald, J.R., 1997. "Generational and steady state genetic algorithms for generator maintenance scheduling problems", Proceedings of the International Conference on Artificial Neural Networks and Genetic Algorithms, pp. 260-264.

[21] Dapazo, J.F., Merrill, H.M., 1975. "Optimal generator maintenance scheduling using integer programming", IEEE Transactions on Power Apparatus and Systems, PAS-94, No. 5, pp. 1537-1545.

[22] Dieulle, L., Bisrenguer, C., Grall, A., Roussingnol, M., 2003. "Sequential condition-based maintenance scheduling for a deteriorating system", European Journal of Operational Research, Vol. 150, Issue 2, pp. 451-461.

[23] Duffuaa, S.O., Al-sultan, K.S., 1997. "Mathematical programming approaches for the management of maintenance, planning and scheduling", Journal of Quality in Maintenance Engineering, Vol. 3, No. 3, pp. 163-176.

[24] Egan, G.T., Dillon, T.S., Morsztyn, K., 1976. "An experimental method of determination of optimal maintenance schedules in power system using branch and bound techniques" IEEE Transactions on Man. and Cybernetics. SMC-6, No. 8, pp. 538-537.

[25] El-Sharkh, M.Y., El-Keib, A.A., Chen, H., 2003. "A fuzzy evolutionary programming-based solution methodology for security-constrained generation maintenance", Electric Power System Research, Vol. 67, Issue 1, pp. 67-72.

[26] El-Sheikhi, F.A., Billinton, R., 1984. "Generating unit maintenance scheduling for single and two interconnected systems", IEEE Transactions on Power Apparatus and Systems, PAS-103, No. 5, pp. 1038-1044.

[27] Enscore, E.E., Burns, D.L., 1983. "Dynamic scheduling of a preventive maintenance programme", International Journal of Production Research, Vol. 21, No. 3, pp. 357-368.

[28] Fielding, D., 1994. "Money demand in four African countries", Journal of Economic Studies, Vol. 21, No. 2.

[29] Fwa, T.F., Cheu, R.L., Muntasir, A., 1999. "Scheduling of pavement 
maintenance to minimise traffic delays", Transportation Research Record 1650, Transportation Research Board, Washington, D.C., pp. 28-35.

[30] Garver, L.L., 1972. "Adjusting maintenance schedule to levelize risk", IEEE Transactions on Power Apparatus and Systems, PAS-91, No. 5, pp. 20572063.

[31] Haghani, A., Shafahi, Y., 2002. "Bus maintenance systems and maintenance scheduling: Model formulation and solutions", Transportation Research Part A: Policy and Practice Vol. 36, Issue 5, pp. 453-458.482

[32] Hall, R.W., 2000. "Scheduling transit railcar maintenance and facility design", Transportation Research, Vol. 34A, pp. 67-84.

[33] Hariga, H., 1994. "A deterministic maintenance-scheduling problem for a group of non-identical machines", International Journal of Operations and Production Management, Vol. 14, No. 7, pp. 27-36.

[34] Higgins, A., Ferreira, L., Lake, M., 1999. "Scheduling rail track maintenance to minimise overall delays", Transportation and traffic theory, Ceder, A. (ed), Pergamon, Kidington, Oxford, Chapter 10, pp. 779-796.

[35] Joshi, S., Gupta, R., 1996. "Scheduling of routine maintenance using production schedules and equipment failure history", Computer and Industrial Engineering, Vol. 10, No. 1, pp. 11-20.

[36] Khatib, H., 1979. "Maintenance scheduling of generating facilities", IEEE Transactions on Power Apparatus and Systems, PAS-98, No. 5, pp. 16041608.

[37] Kin, H., Hayashi, Y., Nara, K., 1997. "An algorithm for thermal unit maintenance scheduling through combined use of GA, SA and TS", IEEE Transactions on Power Systems, Vol. 12, pp. 329-335.

[38] Kobbacy, K. A. H., Fawzi, B. B., Percy, D. F., Ascher, H. E., 1997. "A full history proportional hazards model for preventive maintenance scheduling", Quality and Reliability Engineering, 13, pp. 187-198.

[39] Kurban, M., 1999, "The maintenance schedule optimisation in an interconnected power system using the levelised risk method", IEEE Budapest Power Tech '99 Conference, Budapest, Hungary, 386, pp. 26-40.

[40] Lake, M., Ferreira, L., 2001. "Considering the risk of delays in scheduling railway track maintenance", Proceedings of the $7^{\text {th }}$ International Heavy Haul Conference, International Heavy Haul Association Inc., Virginia Beach, VA, USA, pp. 367-372.

[41] Lake, M., Ferreira, L., Murray, M., 2000. "Minimising costs in scheduling railway track maintenance", Computer in railways VII, Allan, Hill, Brebbia, Scuitto and Sone (eds), WIT Press, Southampton, Chapter 13, pp. 895-902.

[42] Lund, J.R., 1990. "Scheduling maintenance dredging on a single reach with uncertainty", Journal of Waterway, Port, coastal, and ocean engineering, ASCE, Vol. 116, No. 2, pp. 211-321.

[43] Makin, T., 1995. "Inflation distortion of the external accounts: The Australian example", Journal of Economic Studies, Vol. 22, No. 1.

[44] Mallik, G., Chowdhury, A., 2002. "Inflation, government expenditure and real income in the long-run", Journal of Economic Studies, Vol. 29, No. 3, pp. $240-250$.

[45] Marinakis, A.E., 1997. "Wage policy in high inflation countries: The role of indexation in Latin America during the 1980s", Journal of Economic Studies, 
Vol. 24, No. 6, pp. 356 - 378.

[46] Marwali, M., Shahidehpour, M., 1998. "Coordination of short-term and long-term transmission maintenance scheduling in a deregulated system", IEEE Power Engineering Letters, Vol. 1, No. 1, pp. 46-48.

[47] Marwali, M., Shahidehpour, M., 1998. "Integrated generation and transmission maintenance scheduling with network constraints", IEEE Transactions on Power Systems, Vol. 13, No. 3, pp. 1063-1068.

[48] Marwali, M.K.C., Shahidehpour, S.M., 1999. "A probabilistic approach to generation maintenance scheduler with network constraints", International Journal of Electrical Power and Energy Systems, Vol. 21, No. 8, pp. 533-545.

[49] Mosley, S.A., Teyner, T., Uzsoy, R.M., 1998. "Maintenance scheduling and staffing policies in a wafer fabrication facility", IEEE Transactions on Semiconductor Manufacturing, Vol. 11, No. 2, pp. 316 - 323.

[50] Nguyen D.G., Murthy, D.N.P., 1981. "Optimal repair limit replacement policies with imperfect repair", J. Opl. Res. Soc. Vol. 32, pp. 409-416.

[51] Oke S.A, 2004. "Maintenance scheduling: description, status, and future directions", South African Journal of Industrial Engineering, Vol. 15, Issue 1, pp. 101-117.

[52] Park, C. S., 2001. "Contemporary Engineering Economics", Prentice Hall; $3^{\text {rd }}$ Edition; ISBN: 0130893102.

[53] Papapetrou, E., 2001. "Bivariate and multivariate tests of the inflationproductivity Granger-temporal causal relationship: Evidence from Greece", Journal of Economic Studies, Vol. 28, No. 3, pp. 213 - 226.

[54] Percy, D. F., Kobbacy, K, Ascher, H.T., 1998. "Using proportionalintensities models to schedule preventive maintenance intervals", IMA Journal of Mathematical Applied in Business and Industry, Vol. 9, pp. 289-302.

[55] Percy, D.F., Kobbacy, K.A.H, Fawzi, B.B., 1997. "Setting preventive maintenance schedules when data are Sparse", International Journal of Productivity. Economics, Vol. 51, pp. 223-234.

[56] Ram, B., Olumolade, M., 1987. "Preventive maintenance scheduling in the presence of a production plan", Production and Inventory Management, Vol. 8, pp. 81-89.

[57] Samanayake, B.R., Yu, J., 1995. "A balanced maintenance schedule for a failure-prone system", International Journal of Quality and Reliability Management, vol. 12, No. 9, pp. 183-191.

[58] Sarker, B.R., Yu, J., 1995. "A balanced maintenance schedule for a failureprone system", International Journal of Quality and Reliability Management, vol. 12, No. 9, pp. 183-191.

[59] Satoh, T., Nara, K., 1991. "Maintenance scheduling by using the simulated annealing method", IEEE Transactions on Power Systems, Vol. 6, pp. 850-857.

[60] Sepulveda J.A., Souder W.E., Gottfried B.S., 1984. "Schaum's Outline of Engineering Economics", McGraw-Hill ( $1^{\text {st }}$ Edition) ISBN: 0070238340.

[61] Shamsuddin, A.F.M., Homes, R.A., 1997. "Cointegration test of the monetary theory of inflation and forecasting accuracy of the univariate and vector ARMA models of inflation", Journal of Economic Studies, Vol. 24, No. 5, pp. 294 - 306.

[62] Silver, E.A., Murphy, G.F., 1994. "Cost analysis and extension of a simple maintenance scheduling heuristic", NRL (U.S.) Vol. 41, No. 7, pp. 945 - 958. 
[63] Spithoven, A.H.G.M., 1995. "Human capital inflation and unemployment", International Journal of Social Economics, Vol. 22, No. 5, pp. 4 - 14.

[64] Sriram, C., Haghani, A., 2003. "An optimization model for aircraft maintenance scheduling and re-assignment", Transportation Research part A: Policy and Practice; vol. 37, issue 1, pp. 29-48.

[65] Sriskandarajah, C., Jardine, A.K.S., Chan, C.K., 1998. "Maintenance scheduling of rolling stocks using a genetic algorithm", Journal of Operational Research Society (U.K.), Vol. 49, pp. 1130-1145.

[66] Stremel, J.P., 1981. "Maintenance scheduling for generation system planning", IEEE Transactions on Power Apparatus and Systems, PAS-100, No. 3, pp. 4010-4019.

[67] Stremel, J.P., Jenkins, R.T., 1981. "Maintenance scheduling under uncertainty", IEEE Transactions on Power Apparatus and Systems, PAS-100, No. 2, pp. 460-465.

[68] Sullivan W.G., Wicks E.M., Luxhoj J., 2002. "Engineering Economy", Prentice Hall (12 ${ }^{\text {th }}$ Edition) ISBN: 0130673382.

[69] Tegene, A., 1989. "The monetarist explanation of inflation: the experience of six African countries", Journal of Economic Studies, Vol. 16, No. 1.

[70] Walker, L., Bryan, U., Turner, K., 2001. "Scheduling preventive maintenance of transmission circuits", $4^{\text {th }}$ IMA Conference on Modelling in Industrial Maintenance and Reliability Decision Support in the New Millennium, April, 2001, UK.

[71] Wang, Y., Cheu, R.L., Fwa, T.F., 2002. "Highway maintenance scheduling using genetic algorithm with microscopic traffic simulation", Proceedings of the $81^{\text {st }}$ Annual Meeting of the Transportation Research Board, in CD-ROM.

[72] Wirth, A., 1989. "Inventory control and inflation: A review", "International Journal of Operations and Production Management", Vol. 9, No. 1.

[73] Yamayee, Z.A., 1982. "Maintenance scheduling: description, literature survey, and interface with overall operation scheduling", IEEE Transactions on Power Systems, PAS-101, No. 8, pp. 2770-2779.

[74] Yamayee, Z.A., Sidenblad, K., Yoshimura, M., 1998. "A computationally efficient optimal maintenance scheduling method." IEEE Transactions on Power Apparatus and Systems, Vol. 102, No. 2, pp. 330-338.

[75] Yellen, J., Al-Khamis, J., Vemuri, S., Lemonidis, L., 1992. "Unit maintenance scheduling with fuel constraints", IEEE Transactions on Power Systems, 7, pp. 726-733.

[76] Zurn, H.H., Quintana, V.H., 1975. "Generator maintenance scheduling via successive approximations dynamic programming", IEEE Transactions on Power Apparatus and Systems, Vol. 94, No. 2, pp. 665-671.

[77] Zurn, H.H., Quintana, V.H., 1977. "Several objective criteria for optimal generator preventive maintenance scheduling", IEEE Transactions on Power Apparatus and Systems, PAS-96, No. 3, pp. 914-922. 


\section{APPENDIX \\ COMPUTER PROGRAMME FOR INFLATION-BASED MAINTENANCE SCHEDULING MODEL}

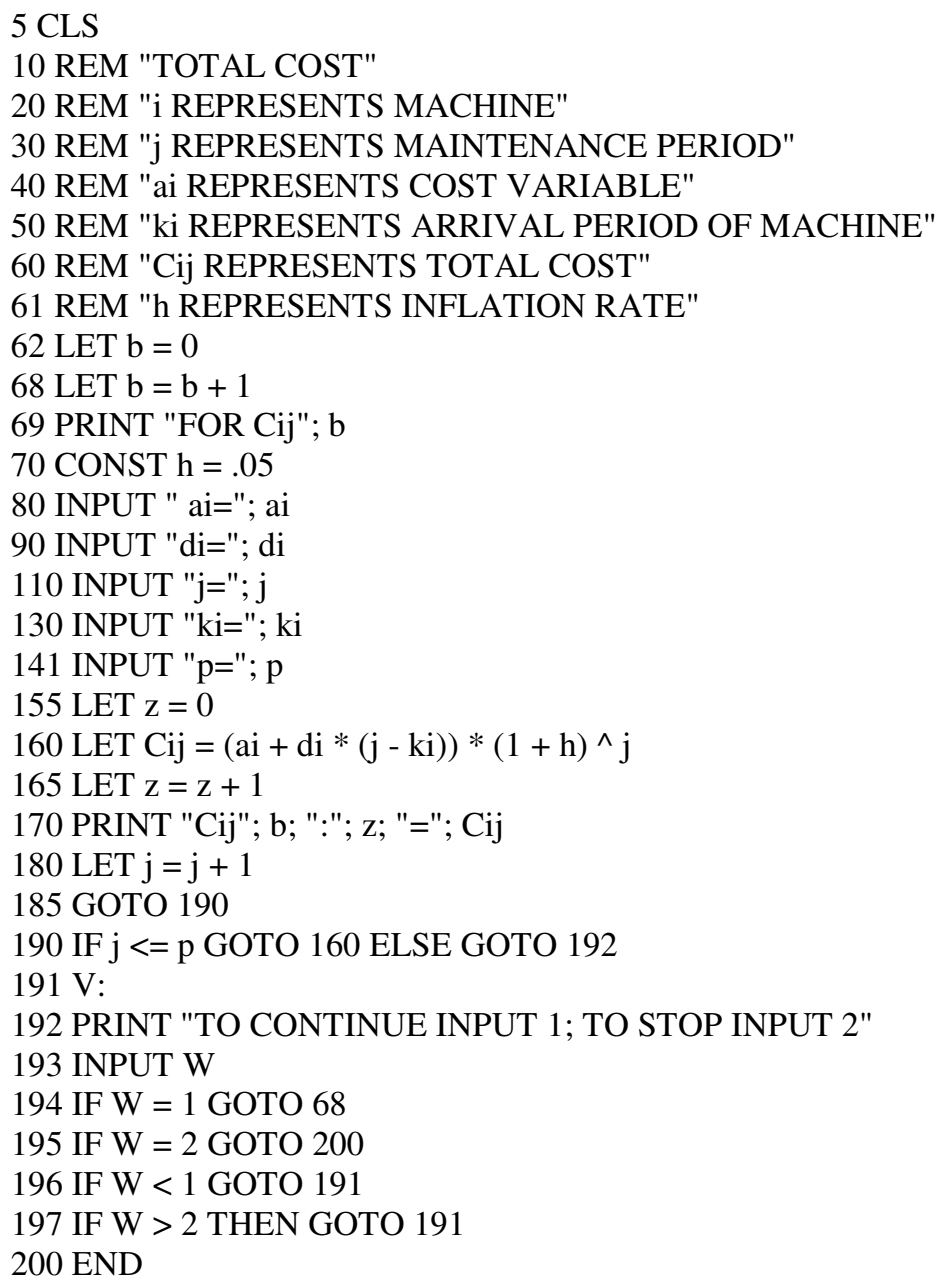

\section{Results}

\section{Input}

FOR Cij 1

$\mathrm{ai}=? \mathbf{1 5 . 2 3} \mathrm{di}=? 3.4 \quad \mathrm{j}=? \mathbf{2} \quad \mathrm{ki}=? 6$

Output

$$
\mathrm{p}=? 15
$$

Cij $1: 1=20.40966$

Cij $1: 2=26.21428$

Cij $1: 6=55.12424$

Cij $1: 5=46.96103$

Cij $1: 10=95.27728$

Cij $1: 3=32.54834$

Cij $1: 4=39.45028$

Cij $1: 9=84.0085$

? 1

\section{Input}

FOR Cij 2

$\mathrm{ai}=$ ? 22

$$
\mathrm{p}=? 15
$$

$\mathrm{di}=? 7.8$

$\mathrm{j}=? 4$

$\mathrm{ki}=? 4$

\section{Output}
Cij $2: 1=26.74114$
Cij $2: 2=38.03319$
Cij $2: 5=78.60063$
Cij $2: 6=94.63102$
Cij $2: 9=151.5703$
Cij $2: 10=173.8569$

TO CONTINUE INPUT 1; TO STOP INPUT 2

Cij $2: 3=50.3876$

Cij $2: 7=112.068$

Cij $2: 11=197.9932$
Cij $2: 4=63.88236$

Cij $2: 8=131.012$

Cij $2: 12=224.1085$ 


\section{Input}

FOR Cij 3

ai=? 18.75

\section{Output}

$$
\mathrm{p}=? 15
$$

$\mathrm{di}=? 4.5$

$\mathrm{j}=? 2$

$\mathrm{ki}=? 2$

Cij $3: 1=20.67188$

Cij $3: 2=26.91478$

Cij $3: 3=33.7303$

Cij $3: 6=58.04289$

Cij $3: 7=67.59359$

Cij $3: 4=41.16008$

Cij $3: 5=49.24852$

Cij $3: 10=101.3376$

Cij $3: 9=89.18198$

Cij $3: 14=160.5972$

Cij $3: 11=114.4858$

Cij $3: 8=77.95425$

Cij $3: 13=144.04$

TO CONTINUE INPUT 1; TO STOP INPUT 2

? 1

\section{Input}

FOR Cij 4

$\mathrm{ai}=? 27.15$

$$
p=? 15
$$

$\mathrm{di}=? 6.3$

$j=$ ? 1

$\mathrm{ki}=? \mathbf{1}$

\section{Output}
Cij $4: 1=28.5075$
Cij $4: 2=36.87862$
Cij $4: 5=66.81334$
Cij $4: 6=78.59661$
Cij $4: 9=120.3055$
Cij $4: 10=136.5828$
Cij $4: 13=193.7505$
Cij $4: 14=215.9115$
TO CONTINUE INPUT 1; TO STOP INPUT 2
? 1

\section{Input}

FOR Cij 5

ai=? 9

$$
\mathrm{p}=? 15
$$

$\mathrm{di}=? 2.2$

$\mathrm{j}=? 7$

Cij $4: 3=46.01559$

Cij $4: 7=91.39117$

Cij $4: 11=154.1871$

Cij $4: 15=239.8044$

Cij $4: 4=55.97406$

Cij $4: 8=105.2687$

Cij $4: 12=173.2103$

\section{Output}

Cij $5: 1=12.6639$

Cij $5: 5=30.44404$

Cij $5: 2=16.5475$

Cij $5: 6=35.91713$

Cij $5: 3=20.7878$

Cij $5: 7=41.86141$

$\mathrm{ki}=? 7$

Cij $5: 9=55.29949$

TO CONTINUE INPUT 1; TO STOP INPUT 2

? 1

\section{Input}

FOR Cij 6

$\mathrm{ai}=$ ? 13

$$
\mathrm{p}=? 15
$$

$\mathrm{di}=? 5.6$

$\mathrm{j}=? \mathbf{1}$

$\mathrm{ki}=$ ? 1

Output
Cij $6: 1=13.65$
Cij $6: 2=20.5065$
Cij $6: 5=45.18037$
Cij $6: 6=54.94392$
Cij $6: 9=89.66677$
Cij $6: 10=103.2719$
Cij $6: 13=151.2291$
Cij $6: 14=169.8781$

TO CONTINUE INPUT 1; TO STOP INPUT 2

? 1

\section{Input}

FOR Cij 7

ai=? 31

$$
\mathrm{p}=? 15
$$

$\mathrm{di}=? 9.6$

Cij $6: 3=28.01452$

Cij $6: 7=65.57088$

Cij $6: 4=36.22209$

Cij $6: 11=118.0134$

Cij $6: 15=190.014$

Cij $5: 4=25.41076$

Cij $5: 8=48.31033$

\section{Output}
Cij $7: 1=39.56473$
Cij $7: 2=54.40788$
Cij $7: 5=107.6622$
Cij $7: 6=128.6827$
Cij $7: 9=203.273$
Cij $7: 10=232.444$

TO CONTINUE INPUT 1; TO STOP INPUT 2

? 1

\section{Output}

FOR Cij 8

$\mathrm{ai}=$ ? 19.5

$$
\mathrm{p}=? 15
$$

Cij $6: 8=77.12318$

Cij $6: 12=133.9709$ cij $7 \cdot 4=88.35184$

Cij $7: 8=176.3531$
Cij $7: 7=151.5361$

Cij $7: 11=264.0239$ $\mathrm{ki}=? 5$

$\mathrm{ki}=$ ? 3 


$\begin{array}{llll}\text { Cij } 8: 1=22.57369 & \text { Cij } 8: 2=29.7799 & \text { Cij } 8: 3=37.65031 & \text { Cij } 8: 4=46.2333 \\ \text { Cij } 8: 5=55.58047 & \text { Cij } 8: 6=65.74677 & \text { Cij } 8: 7=76.79075 & \text { Cij } 8: 8=88.77476 \\ \text { Cij } 8: 9=101.7652 & \text { Cij } 8: 10=115.8327 & \text { Cij } 8: 11=131.0526 & \text { Cij } 8: 12=147.5049 \\ \text { Cij } 8: 13=165.2748 & & & \\ \begin{array}{l}\text { TO CONTINUE INPUT 1; TO STOP INPUT 2 } \\ \begin{array}{l}\text { ? } 1 \\ \text { Input }\end{array}\end{array} & & \\ \begin{array}{l}\text { FOR Cij } 9 \\ \text { ai=? 26.1 }\end{array} & \text { di=? } 8.7 & \text { j=? } 8 & \text { ki=? } 8 \\ \begin{array}{l}\text { Output } \\ \text { Cij } 9: 1=38.56159\end{array} & \text { Cij } 9: 2=53.98622 & \text { Cij } 9: 3=70.85692 & \text { Cij } 9: 4=89.27972 \\ \text { Cij } 9: 5=109.3677 & \text { Cij } 9: 6=131.2412 & \text { Cij } 9: 7=155.0286 & \text { Cij } 9: 8=180.8667\end{array}$

TO CONTINUE INPUT 1; TO STOP INPUT 2

? 1

\section{Input}

FOR Cij 10

$\mathrm{ai}=? 20.4$

$\mathrm{p}=? 15$

$\mathrm{di}=? 7.3$

$j=? 4$

$\mathrm{ki}=? 4$

Output

$\begin{array}{ll}\text { Cij } 10: 1=24.79633 & \text { Cij } 10: 2=35.353 \\ \text { Cij } 10: 5=73.28179 & \text { Cij } 10: 6=88.27058 \\ \text { Cij } 10: 9=141.5135 & \text { Cij } 10: 10=162.3544\end{array}$

Cij $10: 3=46.90335$

Cij $10: 7=104.575$

Cij $10: 11=184.9256$

Cij $10: 4=59.52035$

Cij $10: 8=122.2893$

209.3481

TO CONTINUE INPUT 1; TO STOP INPUT 2

? 1

\section{Input}

FOR Cij 11

$\mathrm{ai}=$ ? 23.12

$$
\mathrm{p}=\text { ? } 15
$$

$\mathrm{di}=? 7.9$

$\mathrm{j}=? 2$

$\mathrm{ki}=? 2$

\section{Input}

Cij $11: 1=25.4898 \quad$ Cij $11: 2=35.90953$

Cij $11: 5=73.33003$

Cij $11: 6=88.11263$

Cij $11: 9=140.6062$

Cij $11: 10=161.1482 \quad$ Cij $11: 11=183.3929$

Cij $11: 3=47.3075$

Cij $11: 4=59.7555$

207.4591

Cij $10: 12=$

Cij $11: 13=233.4735 \quad$ Cij $11: 14=261.5707$

TO CONTINUE INPUT 1; TO STOP INPUT 2

? 1

\section{Input}

FOR Cij 12

$\mathrm{ai}=$ ? 15.7

$$
\mathrm{p}=? 15
$$

$\mathrm{di}=? 4.1$

$\mathrm{j}=$ ? 1

$\mathrm{ki}=?$

\section{Output}

$\begin{array}{ll}\text { Cij } 12: 1=16.485 & \text { Cij } 12: 2=21.8295 \\ \text { Cij } 12: 5=40.96864 & \text { Cij } 12: 6=48.51146 \\ \text { Cij } 12: 9=75.23942 & \text { Cij } 12: 10=85.67986\end{array}$

Cij $12: 3=27.66724$

Cij $11: 8=121.6552$

Cij $11: 11=183.3929$

Cij $11: 12$ = 109.1881

Cij $12: 13=122.3786 \quad$ Cij $12: 14=136.6153$ TO CONTINUE INPUT 1; TO STOP INPUT 2 ? 2

Press any key to continue

Cij $12: 7=56.70615$

Cij $12: 11=96.97624$

Cij $12: 4=34.03418$

Cij $12: 8=65.59902$

Cij 12 : 12 =

Cij $12: 15=151.9697$ 
Figure 1: Period dependent cost against variable ai

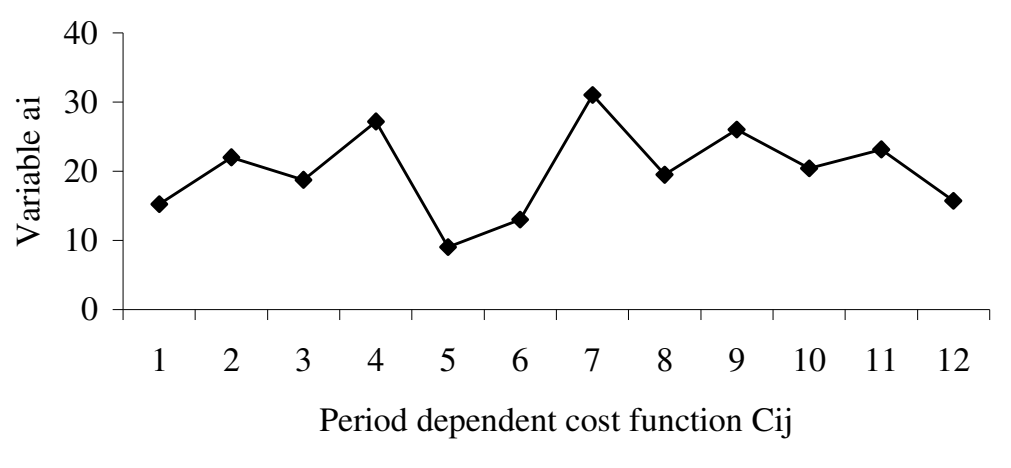

Figure 2: Period dependent cost function and variable di

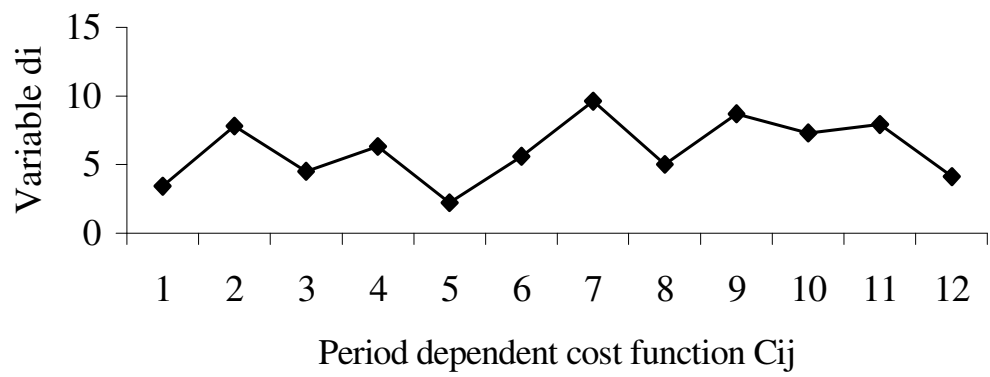

Figure 3: Period dependent cost function and constant variable j

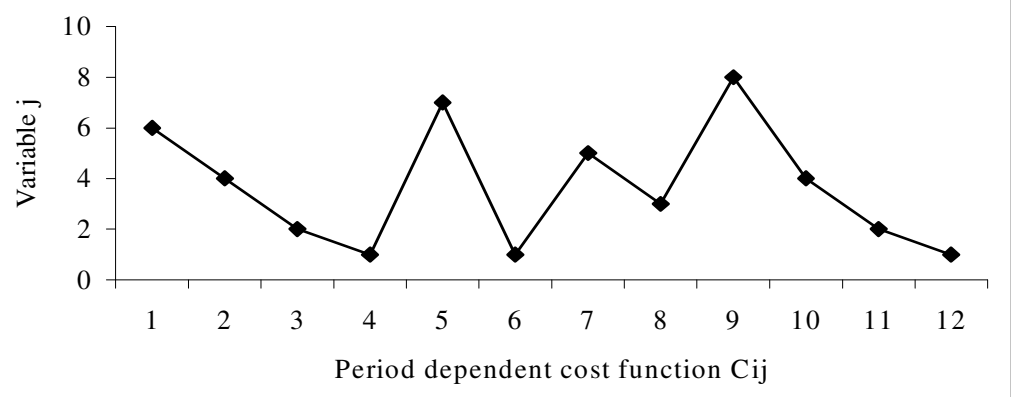

Figure 4: Period dependent cost function and $\mathrm{Ki}$

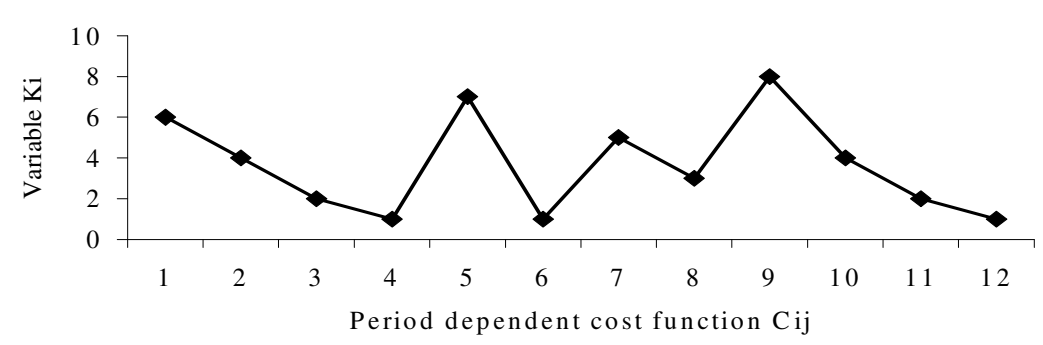

